\title{
NIS two-pressure humidity generator
}

\author{
Doaa Mohamed Abd El-Galil ${ }^{\star}$ and Essam Mahmoud \\ National Institute for Standards NIS, Thermal Metrology Lab, Tersa St. Elharam, El-Giza, P.O. 136, 12211 Giza, Egypt
}

Received: 31 December 2015 / Accepted: 3 May 2016

\begin{abstract}
There are several techniques available to generate humidity references by using stream of saturated gas with well-known water vapor content. Two-pressure humidity generator (2-P) is the most commonly used for the realization of temperature and relative humidity scales at National Institute for standards (NIS) and for disseminating traceability. This generator has been shown to be highly reproducible when properly used. In order to obtain traceable measurements and best performance, the temperature sensors and pressure gauges of this generator should be calibrated. This paper explained the calibration of 2-P temperature sensors and pressure gauges and the analysis of their performance for the first time at NIS.
\end{abstract}

Keywords: Two-pressure humidity generator, calibration, sensor, traceability

\section{Introduction}

The main activities of the thermal metrology laboratory in (NIS) in Egypt in the field of humidity are focused on the maintenance and improvement of standards. In addition, NIS provides humidity calibration services. For getting accurate and uniform humidity measurements inside and outside Egypt. Several hygrometers calibration facilities have been developed at the thermal metrology laboratory at NIS [1]. The humidity is defined as the mass of water vapor in a unit volume of moist air at a given temperature and pressure. This definition implies the need for traceability to temperature and pressure reference standards.

In the field of hygrometry, a primary dew-point standard can be realized according to several proven principles, such as single-pressure (1-P), two-pressure (2-P), or divided flow. Generators with different basic operating principles have been constructed and described by some laboratories. So far, generators working according to either the two-pressure (2-P) have attained the best results. NIS first humidity facility was established in 1997 . It covers the temperature range from $+5{ }^{\circ} \mathrm{C}$ to $+70{ }^{\circ} \mathrm{C}$ and the relative humidity range from $10 \%$ to $90 \%$. NIS humidity generator based on two-pressure principle. The operation of a twopressure humidity generator requires a high pressure air supply, which should be clean, dry and oil free. This pressurized air is driven to the main saturator placed inside of a controlled temperature bath [2]. Temperature and pressure $\left(T_{s}, P_{s}\right)$ are measured at the saturator output, then the saturated air pressure is reduced to about the ambient pressure via an isothermal expansion valve and then

`Correspondence: m.dody74@yahoo.com conducted to the test chamber where the temperature and pressure $\left(T_{c}, P_{c}\right)$ are measured again.

The generator equipped with pressure gauges and temperature sensors. The present work describes the calibration method of 2-P generator sensors and gauges and the analysis of their performance in order to obtain traceable measurements. Brief description of the sensors and the experimental set-up are given next.

\section{Materials and methods}

\subsection{Two-pressure humidity generator}

Operation of the humidity generator is based on the twopressure method of producing known atmospheres of relative humidity and assumes that the water vapor pressure remains a fraction of the total pressure, known as Dalton's Law of Partial Pressure. Dalton's Law states that the pressure exerted by a mixture of gases in a given volume at some temperature is equal to the sum of the pressures which would be exerted by each individual gas if it alone occupied the volume at the same temperature. Equation (1) shows how to calculate relative humidity using a two-pressure generator [3].

$$
\% R H=\frac{e w\left(T_{s}\right)}{e w\left(T_{c}\right)} \times \frac{P_{c}}{P_{s}} \times 100
$$

where $e w\left(T_{s}\right)$ - the saturation vapor pressure at the saturation temperature, $T_{s}$, ew $\left(T_{c}\right)$ - the saturation vapor pressure at the chamber temperature, $T_{c}, P_{c}$ - the absolute pressure in the chamber, and $P_{s}$ - the absolute pressure in the saturator. 


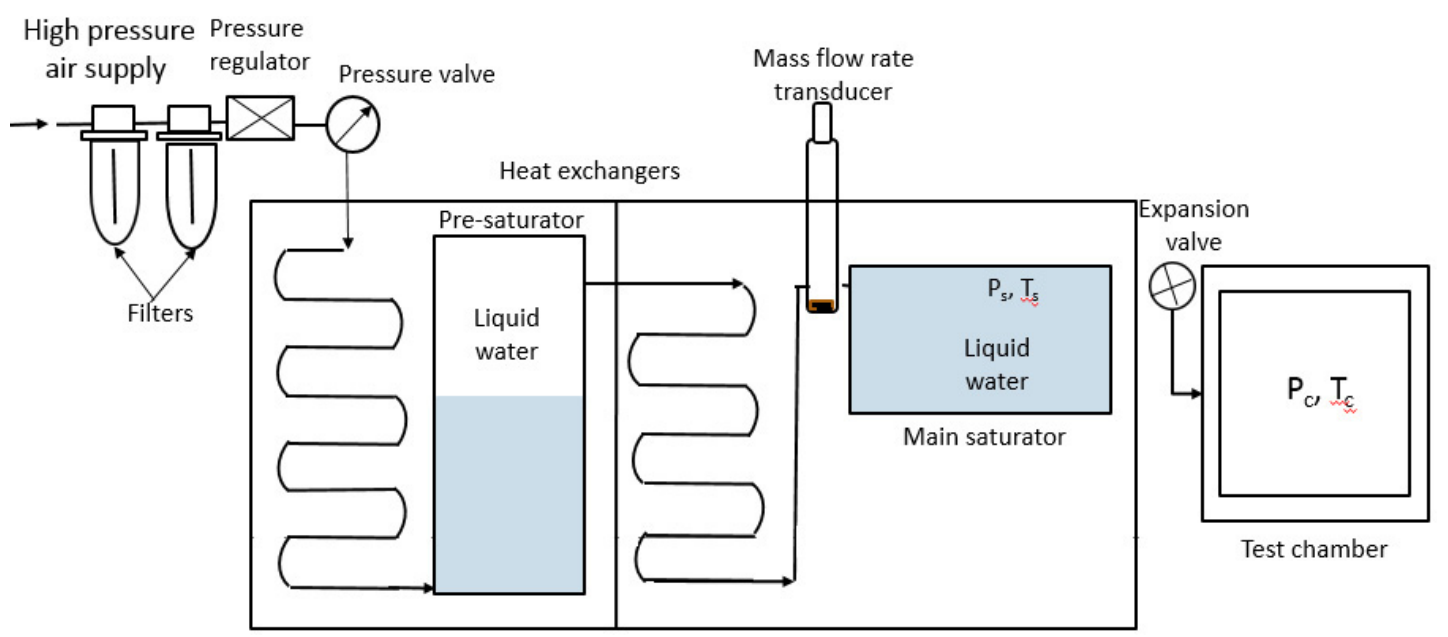

Fig. 1. Schematic diagram of two-pressure humidity generator.

Figure 1 shows a schematic diagram of two-pressure humidity generator involves saturating air, with water vapor at a given pressure and temperature. The saturated gas then flows through an expansion valve where it is isothermally reduced to chamber pressure. If the temperature of the gas is held constant during pressure reduction, the humidity, at chamber pressure, may then be approximated as the ratio of two absolute pressures.

\subsection{Description and calibration of the temperature sensors}

Four $1 \mathrm{~K} \Omega$ thermistors are used in the two-pressure humidity generator temperature read out and control. One of them is (RTD 0) inserted in the saturator to measure and control the saturation temperature. Another one is (RTD 1) inserted in the pre-saturator to measure and controls the pre-saturation temperature. The third one (RTD 2) is inserted in the expansion valve to measure and control the expansion valve temperature. Measuring the temperature of the test chamber will be done by the last one (RTD 3) [4].

Calibration of the generator temperature sensors carried out by comparison with Fluke calibrated Platinum Resistance Thermometer (PRT) and calibrated Resistance Bridge for disseminating traceability. Figure 2 shows the traceability route for humidity. Fluke calibrated temperature calibration Metrology well with high stability for the range of $0{ }^{\circ} \mathrm{C}$ to $70{ }^{\circ} \mathrm{C}$ used as a medium [5]. The calibration was carried out at three points of calibration $\left(0^{\circ} \mathrm{C}\right.$, $35^{\circ} \mathrm{C}$ and $70^{\circ} \mathrm{C}$ ) from the lower to the higher or vice versa as recommendation from the generator catalogue. The resolution of the generator indicator is $0.001{ }^{\circ} \mathrm{C}$ at $0{ }^{\circ} \mathrm{C}$ only and $0.01{ }^{\circ} \mathrm{C}$ at $35^{\circ} \mathrm{C}$ and $70{ }^{\circ} \mathrm{C}$.

The temperature sensors of the generator were removed out for the first time from the jacket of the generator and then installed in the temperature metrology well. Figure 3 shows the setup of the calibration system.

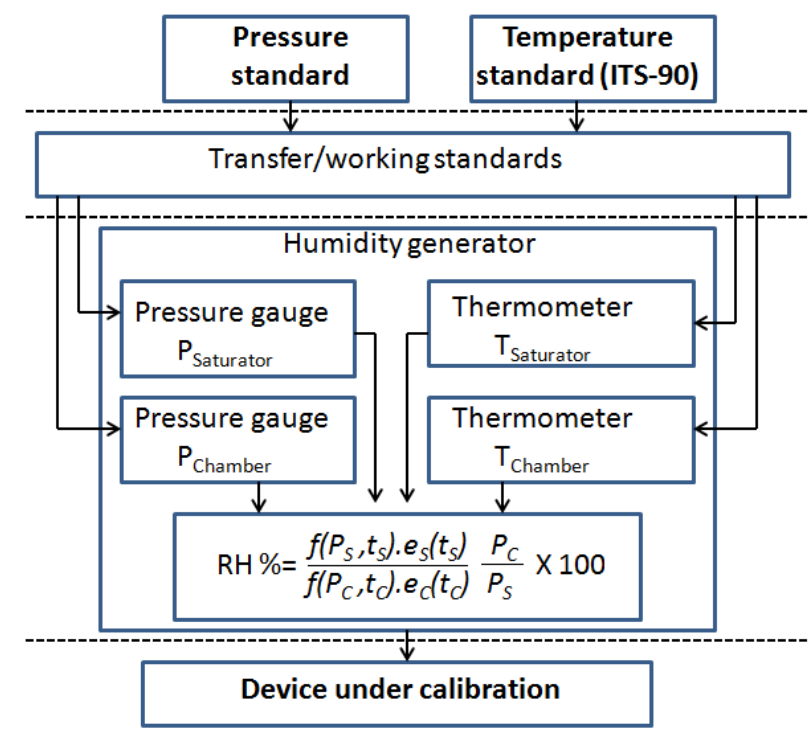

Fig. 2. Traceability route for humidity.

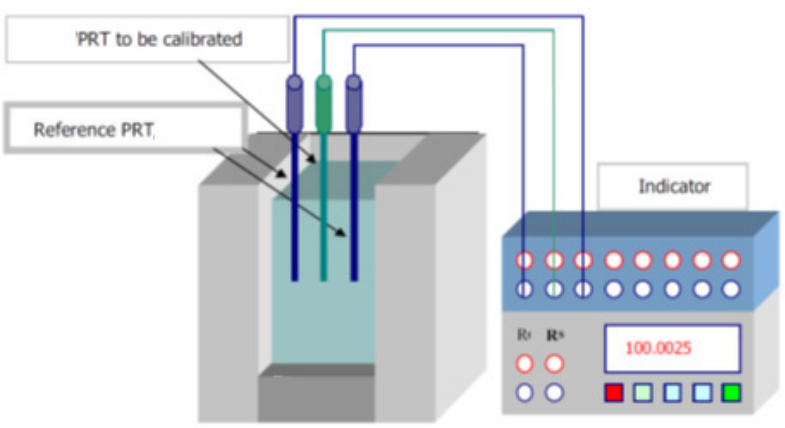

Fig. 3. Setup of the calibration system.

Firstly, adjust the temperature of the Metrology well to the required calibration point and wait for stability. Normally start the first point from the lower to the higher temperature. When the temperature of reference 


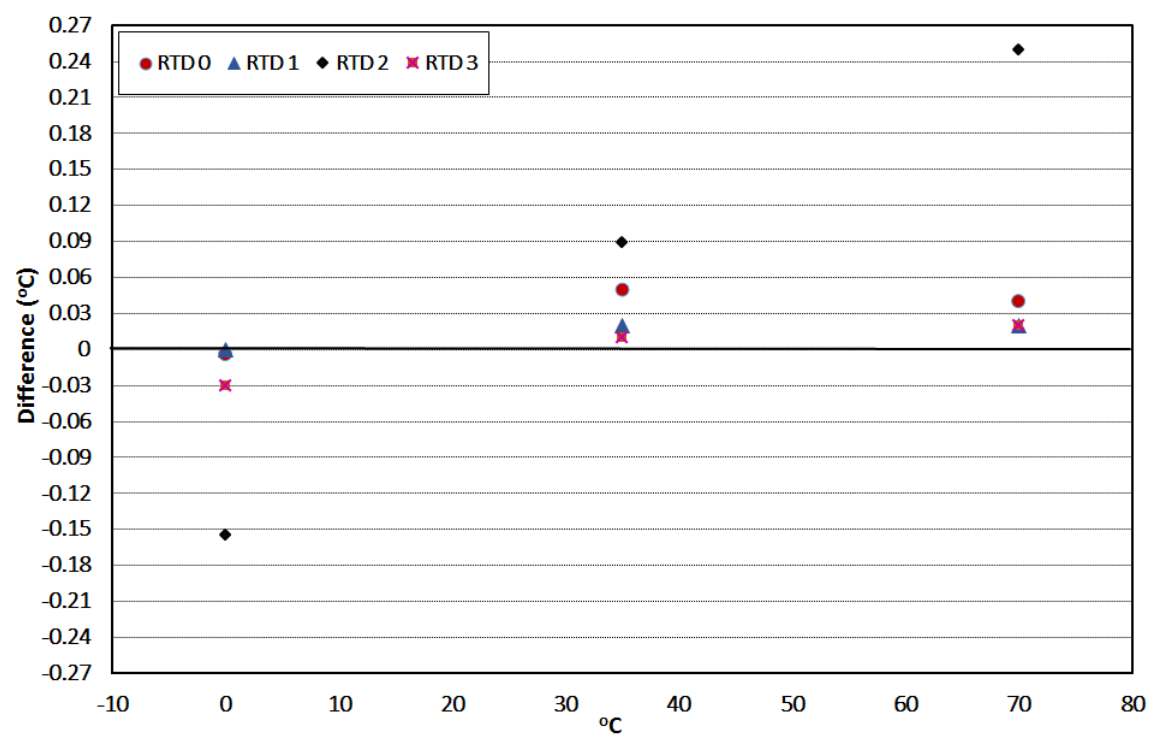

Fig. 4. Temperature difference between the reference standard and the generator temperature sensors.

thermometer becomes stable as observed on high resolution temperature read out, the PRT resistance is measured and recorded at each temperature. Then calculate the mean value and standard deviation. Insert the values of the thermometer as a constant to the generator software for the three temperature points of the calibration that have been taken. Calibration coefficients were calculated automatically by the embedded generator software and stored in the generator memory. At the end, re-install all the temperature sensors in their previous places.

\subsection{Description and calibration of the pressure gauges}

Two pressure transducers (low-pressure (0-50 psiA) and high-pressure (50-150 psiA)) are used in two-pressure humidity generator for pressure readout and control Uniformly distributed points are used for the calibration.

The comparison between the measurement values for pressure transducer and reference standard can be performed by two different methods:

1- Adjustment of the pressure according to the indication of the pressure transducer.

2- Adjustment of the pressure according to the indication of the standard.

In this paper, we used the second method which is according to indication of the standard. Comparison method based on DKD R 6-1, 2003 using remote pressure sensor displayed with DPI 615 of accuracy class $0.025 \%$ of full scale.

The time for preloading at the highest value and the time between two preloadings should be at least 30 s. For the pressure step variation, the time between two successive load steps should be the same and not be shorter than $30 \mathrm{~s}$ and the reading should be made $30 \mathrm{~s}$ after the
Table 1. The results of the calibration of the temperature sensors.

\begin{tabular}{ccccc}
\hline $\begin{array}{c}\text { Reference } \\
\text { temperature } \\
{ }^{\circ} \mathrm{C}\end{array}$ & $\begin{array}{c}\text { RTD 0 } \\
\text { reading } \\
{ }^{\circ} \mathrm{C}\end{array}$ & $\begin{array}{c}\text { RTD 1 } \\
\text { reading } \\
{ }^{\circ} \mathrm{C}\end{array}$ & $\begin{array}{c}\text { RTD 2 } \\
\text { reading } \\
{ }^{\circ} \mathrm{C}\end{array}$ & $\begin{array}{c}\text { RTD 3 } \\
\text { reading } \\
{ }^{\circ} \mathrm{C}\end{array}$ \\
\hline 0.000 & +0.004 & 0.000 & +0.154 & +0.029 \\
35.000 & 34.95 & 34.98 & 34.91 & 34.99 \\
70.000 & 69.96 & 69.98 & 69.75 & 69.98 \\
\hline
\end{tabular}

start of the pressure change at the earliest. The measurement value for the upper limit of the calibration range is to be recorded prior to and after the waiting time. The calibration coefficients were calculated automatically by the embedded generator software and stored in the generator memory.

\section{Results}

The results of the calibration of the temperature sensors obtained were depicted in Table 1 and Figure 4. For each generated temperature the difference between the reference reading and the reading of temperature sensor was calculated and plotted as a function of temperature. As shown, all differences were within $0.05{ }^{\circ} \mathrm{C}$ except for RTD 2 it has largest temperature differences from -0.15 to $0.25^{\circ} \mathrm{C}$. Nevertheless, it does not make any significant effect in the overall performance of the generator. The arithmetic mean and standard deviation can be considered suitable statistics for summarizing the data obtained per each sensor and also for the whole set [4].

All temperature values from the calibration were entered in the generator software to calculate the new coefficients per each temperature sensor.

New coefficients were calculated to get correct and accurate readings from the two-pressure humidity generator. 
Table 2. The uncertainty budget of the generator temperature sensors.

\begin{tabular}{|c|c|c|c|c|c|c|}
\hline Symbol & Source uncertainty & $\begin{array}{c}\text { Value } \\
X_{i} \pm\left({ }^{\circ} \mathrm{C}, \Omega\right)\end{array}$ & Divisor & $\begin{array}{l}\text { Sensitivity } \\
\text { coefficient }\end{array}$ & $\begin{array}{l}\text { Uncertainty } \\
\text { contribution }\end{array}$ & $\begin{array}{l}\text { Method of } \\
\text { estimation }\end{array}$ \\
\hline$U_{\text {st1 }}$ & $\begin{array}{l}\text { Uncertainty } \\
\text { of Standard }\end{array}$ & 0.001 & 2 & 1 & 0.0005 & $\begin{array}{c}\text { Calibration } \\
\text { certificate }\end{array}$ \\
\hline$U_{\text {res }}$ & Resolution & 0.0001 & 3.46 & 1 & $2.88675 \mathrm{E}-05$ & $\begin{array}{l}\text { Digital indicator } \\
=0.5 \text { of resolution }\end{array}$ \\
\hline$U_{\text {mul }}$ & Bridge & 0.0003 & 2 & 2.5 & 0.00037 & $\begin{array}{c}\text { Calibration } \\
\text { certificate }\end{array}$ \\
\hline$U_{\mathrm{drf}}$ & Drift of Bridge & 0 & 2 & 1 & 0 & $\begin{array}{l}\text { Max. Difference } \\
\text { between two } \\
\text { successive } \\
\text { calibrations of } \\
\text { the standard }\end{array}$ \\
\hline$U_{\text {res uut }}$ & Resolution of UUT & 0.001 & 3.46 & 1 & 0.000288 & $\begin{array}{l}\text { Digital indicator } \\
=0.5 \text { of resolution }\end{array}$ \\
\hline$U_{\text {axi }}$ & Axial of dry block & 0.001 & 1.73 & 1 & 0.000577 & $\begin{array}{c}\text { max difference } \\
\text { between dry block } \\
\text { holes for axial } \\
\text { measurement }\end{array}$ \\
\hline$U_{\mathrm{rad}}$ & Radial of dry block & 0.005 & 1.73 & 1 & 0.002886 & $\begin{array}{c}\text { max difference } \\
\text { between dry block } \\
\text { holes for radial } \\
\text { measurement }\end{array}$ \\
\hline$U_{\text {stab }}$ & Stability of dry block & 0.04 & 3.46 & 1 & 0.014433 & $\begin{array}{l}\text { difference between } \\
\text { maximum and } \\
\text { minimum value } \\
\text { of measurements }\end{array}$ \\
\hline$U_{\text {hyst }}$ & Hysteresis effects & 0.01 & 1.73 & 1 & 0.005773 & $\begin{array}{c}\text { Max difference } \\
\text { between increase } \\
\text { and decrease } \\
\text { measurements }\end{array}$ \\
\hline$U_{\text {rep }}$ & Repeatability(A) & 0.002 & 1 & 0.0777 & 0.00015 & $\begin{array}{c}\text { Standard } \\
\text { deviation of } \\
\text { measurements }\end{array}$ \\
\hline & Combined Un. & & & & 0.012 & \\
\hline & Expanded Un. & & & & $\pm 0.024{ }^{\circ} \mathrm{C}$ & \\
\hline
\end{tabular}

The expanded uncertainty of measurements is described by an uncertainty budget [6]. The measurement uncertainty for the temperature sensors of two-pressure humidity generator was estimated to be about $\pm 0.2{ }^{\circ} \mathrm{C}$. Table 2 shows the calculated uncertainty budget.

The uncertainty budget comprises a composite of the uncertainties of each element and the method of estimation for each element.

The calibration of pressure transducers was done for low and high pressure. The difference between the reference value and the low pressure transducer is shown in Table 3. Raising and falling measurements are very close from each other. The maximum difference between raising and falling is $0.02 \mathrm{psiA}$. The measurement uncertainty for the low pressure transducer of two-pressure humidity generator was estimated to be about $\pm 11 \times 10^{-3} \mathrm{psiA}$. Table 4 shows the calculated uncertainty budget for the low pressure transducer. The uncertainty budget comprises a composite of the uncertainties of each element and the method of estimation for each element.

The difference between the reference value and the high pressure transducer is shown in Table 5. Raising and falling measurements are very close from each other. The maximum difference between raising and falling is $0.03 \mathrm{psiA}$. The measurement uncertainty for the high pressure transducer of two-pressure humidity generator was estimated to be about $\pm 22 \times 10^{-3}$ psiA. Table 6 shows the calculated uncertainty budget for the high pressure transducer. The uncertainty budget comprises a composite of the uncertainties of each element and the method of estimation for each element.

The reported expanded uncertainty is based on GUM standard, and the standard uncertainty multiplied by coverage factor $(k=2)$ to give confidence level of $95 \%$ [7].

The uncertainty was calculated at full scale. The calculation does not include the hysteresis component. 
Table 3. The difference between the reference value and the low pressure transducer.

\begin{tabular}{cccc}
\hline $\begin{array}{c}\text { Transducer } \\
\text { reading }(\mathrm{psiA})\end{array}$ & \multicolumn{2}{c}{ Mean reference value (psiA) } & $\begin{array}{c}U \\
\text { psiA }\end{array}$ \\
\cline { 2 - 3 } & Pressure raising & Pressure falling & $\pm 11 \times 10^{-3}$ \\
5 & 5.09 & 5.09 & \\
10 & 10.08 & 10.08 & \\
20 & 15.07 & 15.07 & \\
25 & 20.06 & 20.05 & \\
30 & 25.05 & 25.04 & \\
35 & 30.03 & 30.02 & \\
40 & 35.02 & 35.01 & \\
45 & 40.00 & 39.99 & \\
50 & 45.00 & 44.98 & \\
\hline
\end{tabular}

Table 4. The uncertainty budget of the generator low pressure transducer.

\begin{tabular}{|c|c|c|c|c|c|c|}
\hline Symbol & $\begin{array}{c}\text { Source of } \\
\text { Uncertainty }\end{array}$ & Value & Divisor & $\begin{array}{l}\text { Sensitivity } \\
\text { coefficient }\end{array}$ & $\begin{array}{l}\text { Uncertainty } \\
\text { contribution }\end{array}$ & $\begin{array}{l}\text { Method of } \\
\text { estimation }\end{array}$ \\
\hline \multicolumn{7}{|c|}{ Type A } \\
\hline$U_{\text {rep }}$ & $\begin{array}{l}\text { Repeatability } \\
\text { of } \\
\text { measurements }\end{array}$ & 0.00333 & 1 & 1 & 0.00333 & $\begin{array}{c}\text { Standard } \\
\text { deviation of } \\
\text { measurements }\end{array}$ \\
\hline \multicolumn{7}{|c|}{ Type B } \\
\hline$U_{\mathrm{STD}}$ & $\begin{array}{c}\text { Calibration of } \\
\text { standard }\end{array}$ & 0.006 & 2 & 1 & 0.003 & $\begin{array}{c}\text { Calibration } \\
\text { certificate }\end{array}$ \\
\hline$U_{\text {hys }}$ & $\begin{array}{l}\text { Hysteresis of } \\
\text { measurements }\end{array}$ & 0 & 1.73 & 1 & 0 & $\begin{array}{l}\text { Max difference } \\
\text { between } \\
\text { increase and } \\
\text { decrease } \\
\text { measurements }\end{array}$ \\
\hline$U_{\mathrm{s}}$ & $\begin{array}{l}\text { Resolution } \\
\text { of the UUT }\end{array}$ & 0.005 & 1.73 & 1 & 0.00288 & $\begin{array}{c}\text { Dial gauge }= \\
0.2 \text { of resolution }\end{array}$ \\
\hline & & & & & & $\begin{array}{c}\text { Digital }= \\
0.5 \text { of resolution }\end{array}$ \\
\hline \multirow[t]{2}{*}{$U_{\mathrm{D}}$} & $\begin{array}{c}\text { Drift } \\
\text { of the } \\
\text { Standard }\end{array}$ & 0.0012 & 1.73 & 1 & 0.00069 & $\begin{array}{c}\text { Max. Difference } \\
\text { between two } \\
\text { successive } \\
\text { calibrations of } \\
\text { standard } \\
\end{array}$ \\
\hline & $\begin{array}{c}\text { Uncorrected } \\
\text { error of the gauge } \\
\text { the gauge }\end{array}$ & 0.003 & 1.73 & 1 & 0.00173 & $\begin{array}{l}\text { Calibration } \\
\text { certificate }\end{array}$ \\
\hline$U_{\mathrm{c}}$ & $\begin{array}{c}\text { Combined } \\
\text { uncertainty }\end{array}$ & & & & 0.0056 & \\
\hline$U$ & $\begin{array}{l}\text { Expanded } \\
\text { uncertainty }\end{array}$ & & & & \pm 0.0113 psiA & \\
\hline
\end{tabular}

\section{Conclusions}

To obtain traceable measurements and best performance, temperature sensors and pressure transducers of NIS twopressure humidity generate were successfully calibrated. The coefficients of the generator were calculated automatically by the embedded generator software and stored in the generator memory after entering the new values of the calibrated temperature sensors at $\left(0{ }^{\circ} \mathrm{C}, 35{ }^{\circ} \mathrm{C}\right.$ and $70{ }^{\circ} \mathrm{C}$ ) and calibrated two pressure transducers (lowpressure (0-50 psiA) and high-pressure (50-150 psiA)). The evaluation of uncertainty budget were found to be $\pm 0.02{ }^{\circ} \mathrm{C}$ and $( \pm 11 \times 103 \mathrm{psiA}, \pm 22 \times 103 \mathrm{psiA})$ for temperature sensors and pressure transducers respectively. This ensure that NIS two-pressure humidity generator provide traceable calibrations for dew-point meters and 
Table 5. The difference between the reference value and the high pressure transducer.

\begin{tabular}{cccc}
\hline Transducer & \multicolumn{2}{c}{ Mean reference value (psiA) } & $\begin{array}{c}U \\
\text { reading }(\text { psiA) }\end{array}$ \\
\cline { 2 - 3 } & Pressure raising & Pressure falling & $\pm 22 \times 10^{-3}$ \\
\hline 14.52 & 14.74 & 14.74 & \\
20 & 20.23 & 20.23 & \\
35 & 35.20 & 35.20 & \\
50 & 50.19 & 50.18 & \\
70 & 70.18 & 70.16 & \\
85 & 85.16 & 85.15 & \\
100 & 100.15 & 100.12 & \\
115 & 115.14 & 115.14 & \\
130 & 130.14 & 130.13 & \\
150 & 150.13 & 150.13 & \\
\hline
\end{tabular}

Table 6. The uncertainty budget of the generator high pressure transducer.

\begin{tabular}{|c|c|c|c|c|c|c|}
\hline Symbol & $\begin{array}{c}\text { Source of } \\
\text { uncertainty }\end{array}$ & Value & Divisor & $\begin{array}{l}\text { Sensitivity } \\
\text { coefficient }\end{array}$ & $\begin{array}{l}\text { Uncertainty } \\
\text { contribution }\end{array}$ & $\begin{array}{l}\text { Method of } \\
\text { estimation }\end{array}$ \\
\hline \multicolumn{7}{|c|}{ Type A } \\
\hline$U_{\text {rep }}$ & $\begin{array}{l}\text { Repeatability } \\
\text { of } \\
\text { measurements }\end{array}$ & 0.0057 & 1 & 1 & 0.0057 & $\begin{array}{c}\text { Standard } \\
\text { deviation of } \\
\text { measurements }\end{array}$ \\
\hline \multicolumn{7}{|c|}{ Type B } \\
\hline$U_{\mathrm{STD}}$ & $\begin{array}{l}\text { Calibration } \\
\text { of standard }\end{array}$ & 0.0146 & 2 & 1 & 0.0073 & $\begin{array}{c}\text { Calibration } \\
\text { certificate } \\
\end{array}$ \\
\hline$U_{\text {hys }}$ & $\begin{array}{l}\text { Hysteresis of } \\
\text { measurements }\end{array}$ & 0 & 1.73 & 1 & 0 & $\begin{array}{c}\text { Max difference } \\
\text { between increase } \\
\text { and decrease } \\
\text { measurements }\end{array}$ \\
\hline$U_{\mathrm{s}}$ & $\begin{array}{l}\text { Resolution } \\
\text { of the UUT }\end{array}$ & 0.005 & 1.73 & 1 & 0.0028 & $\begin{array}{c}\text { Dial gauge }= \\
0.2 \text { of resolution }\end{array}$ \\
\hline \multirow[t]{2}{*}{$U_{\mathrm{D}}$} & $\begin{array}{c}\text { Drift } \\
\text { of the } \\
\text { Standard }\end{array}$ & 0.0029 & 1.73 & 1 & 0.0016 & $\begin{array}{l}\text { Max. Difference } \\
\text { between two } \\
\text { successive } \\
\text { calibrations of } \\
\text { the standard }\end{array}$ \\
\hline & $\begin{array}{l}\text { Uncorrected } \\
\text { error of } \\
\text { the gauge }\end{array}$ & 0.0073 & 1.73 & 1 & 0.0042 & $\begin{array}{l}\text { Calibration } \\
\text { certificate }\end{array}$ \\
\hline$U_{\mathrm{c}}$ & $\begin{array}{c}\text { Combined } \\
\text { uncertainty }\end{array}$ & & & & 0.0107 & \\
\hline$U$ & $\begin{array}{c}\text { Expanded } \\
\text { uncertainty }\end{array}$ & & & & $\pm 0.0215 \mathrm{psiA}$ & \\
\hline
\end{tabular}

all other types of thermo-hygrometer in the temperature range from $+5{ }^{\circ} \mathrm{C}$ to $+70{ }^{\circ} \mathrm{C}$ and the relative humidity range from $10 \%$ to $90 \%$.

\section{References}

1. M. Gamal Ahmed, S. Mazen, D. Abd El-Gelil, Development of NIS Two-Temperature Humidity Generator, J. Phys. Sci. Appl. 4 (2014)

2. S. Ugur, A. Uttum, Characterization of UME two-pressure humidity generator, Tubitak. UME Gebze, Turkey, ISHM, 2002

3. E. El-Din, M. Mahmoud Mekawy, K. Mohamed Ali, Realization Of Humidity Standard Facility Using TwoPressure Humidity Generator and Humidity Chamber, Metrology and Measurement Systems Index 330930, ISSN 0860-8229 (2009)
4. R. Benyon, T. Vicente, Consistency of the National Realization of Dew-Point Temperature Using Standard Humidity Generators, Int. J. Thermophys. 33, 1550-1558 (2012)

5. IEC 60751:2008, Industrial platinum resistance thermometers and platinum temperature sensors

6. F.M. Megahed, Y.A. Abdelaziz, Uncertainty evaluation in the calibration of $\mathrm{Pt} / \mathrm{Pd}$ thermocouples up to copper freezing point at NIS-Egypt, Int. J. Metrol. Qual. Eng. 2, 13-17 (2011)

7. ISO GUM, 1995, Guide to the expression of the uncertainty in measurement, BIPM, IEC, IFCC, ISO, IUPAP, IUPAC, OIML 